\title{
TRENDS AND CAUSES OF CONGENITAL ANOMALIES IN THE PLEVEN REGION, BULGARIA
}

\author{
Kovacheva $\mathrm{K}^{1^{*}}$, Simeonova $\mathrm{M}^{1}$, Velkova $\mathrm{A}^{2}$
}

\begin{abstract}
*Corresponding author: Katya Kovacheva, Department of Medical Genetics, Medical University, 1, Kliment Ohridski str., Pleven 5800, Bulgaria; Tel.: +359-6488-4169; Fax: +359-6482-2667; E-mail: katiakovach@gmail.com
\end{abstract}

\begin{abstract}
We describe the secular trend, pattern and causes of congenital anomalies (CAs) in the Pleven region, Bulgaria. The source of the data was the regional population-based registry of CAs using criteria according to EUROCAT recommendations. During the period 1988-2006, 47,622 births were surveyed. A total of 1,225 cases of CAs were ascertained, giving a total prevalence of 25.72 [ $95 \%$ confidence interval ( $95 \%$ CI) 24.3 to 27.15 per 1,000 births. There was a significant increase in total prevalence from 17.76 per 1,000 births in 1988 to 29.40 in 2006 ( $\chi 2$ test for trend $=5.03 ; p=0.025)$. Congenital heart disease (4.3 per 1,000 registered births), nervous system anomalies (3.3 per 1,000 births), limb defects ( 2.5 per 1,000 births) and neural tube defects (2.0 per 1,000 births) demonstrated the highest prevalence. There was a significant upward trend in the prevalence of some specific anomalies: digestive system, tumors, gastroschisis and non syndromal dysmorphologic conditions. Genetic causes were identified in approximately $62 \%$ of all cases with CAs (chromosomal $8 \%$, single gene defects $14 \%$, multifacto-
\end{abstract}

1 Department of Medical Genetics, Medical Faculty, Medical University, Pleven, Bulgaria

2 Department of Social and Preventive Medicine, Faculty of Public Health, Medical University, Pleven, Bulgaria rial 40\%). The secular trend and particular pattern of CAs in the Pleven region require some potential underlying contributing factors to be considered: case ascertainment and diagnostic methods, and some environmental factors. These data draw attention to the need of further regional epidemiological studies. The high proportion of genetic causes emphasize the role of genetic services as an integral part of preventive medical care.

Keywords: Causes, Congenital anomalies, Prevalence, Regional registry, Secular trend

\section{INTRODUCTION}

Congenital anomalies (CAs) affect approximately $2-3 \%$ of all live births every year. Many of these defects are associated with serious health problems. Despite the geographical differences in the reported prevalence of CAs, they are still a leading cause of perinatal mortality and childhood morbidity [1-5]. Over the past 20 years, significant progress has been made in understanding the etiology of birth defects. There are many recognized causes of CAs, although in many cases no clear explanation can be established. The availability of antenatal and neonatal screening promotes the early diagnosis of CAs and provides information about their prevalence by using a regional registration approach. The good epidemiological data on the prevalence rate and pattern of birth defects in a specific region gives an opportunity of identifying some etiological factors and can be useful for their prevention. 
The aim of this study was to describe the epidemiology of CAs in the region of Pleven (Bulgaria) over the period 1988-2006, and to answer the following questions: what is the prevalence of CAs? Has there been a secular change in the prevalence of CAs? What is the pattern of CAs? Which are the main causes of CAs and what is the role of genetic causes in their etiology?

\section{METHODS}

Study Population. The data in the study is based on the registry of CAs located at the University Hospital, City of Pleven, Bulgaria. This is a regional registry, not financially supported by the Ministry of Health, dealing with between 2,000 and 3,000 births per year. The registry is population based; University Hospital is the only hospital in the city and covers all deliveries of resident women within the boundaries of the Pleven region, a region with a decreasing number of inhabitants over the study period (from about 160,000 in 1988 to 140,500 in 2006). Invasive prenatal diagnosis is not available in the Pleven region. Over the period 1988-2006, a total of 47,622 births was surveyed, of which $47,229(99.2 \%)$ were live births and 393 $(0.8 \%)$ stillbirths.

Case Definition, Classification of Congenital Anomalies, and Ascertainment. The registry records all CAs identified in live births, stillbirths (official statistics of fetal deaths at $\geq 28$ weeks gestation until 1992 and at $\geq 24$ weeks gestation after 1992) including late miscarriages (fetal deaths of $\geq 20$ weeks gestation), and terminations of pregnancy following prenatal diagnosis of CA. Early fetal deaths before the 20th week of gestation were excluded. The case definition and definition of CA were taken according to EUROCAT recommendations [6].

The congenital anomalies inclusion list comprised mainly major CAs and some minor anomalies without medical or cosmetic significance, either malformations or deformations (for example, isolated talipes). Some minor anomalies (EUROCAT list of minor anomalies for exclusion) were not recorded [6]. Cases with "isolated" anomalies were classified according to the EUROCAT classification by organ system or body region (e.g., neural system, heart, digestive system). Cases with three or more CAs were classified as "multiple anomalies" and comprised: chromosomal abnormalities, single gene and sporadic malformation syndromes [7], non syndromal dysmorphologic conditions (sequence/ association/complex), teratogenic syndromes (environmental abnormalities), multiple anomalies of unknown cause (malformation syndromes with unknown etiology and nosology). The anomalies assigned to the "multifactorial" category included the following isolated anomalies: neural tube defects (NTD); congenital heart disease (CHD); cleft palate and cleft lip; some cases of CAs of the nervous system (Dandy-Walker malformation, hydrocephaly due to congenital stenosis of the aqueduct of Sylvius); esophageal atresia/stenosis/tracheo-esophageal fistula; hypospadias; family cases of pes equinovarus and luxatio coxae congenita; congenital pyloric stenosis.

The criteria for inclusion of CHD cases were as follows: only cases of isolated cardiac defects in which the diagnosis was made by a cardiologist and confirmed by echocardiography or invasive criteria (catheter studies, surgery or pathological examination) were included. Functional or unspecified cardiac murmurs were excluded.

The ascertainment of the cases was mainly $(90 \%$ of all cases) based on an active searching/screening for CAs conducted by neonatologists, gynecologists and clinical geneticists. Additional sources of information were hospital records (departments of obstetrics and gynecology, neonatology and pediatrics), records of pathological meetings, medical genetics records and stillbirths register. Whatever the source of ascertainment, at the end of every year all registered CA cases (particularly those with multiple anomalies) were carefully reviewed by a clinical geneticist to validate the diagnostic information, to check ID information and to record the final diagnosis. In all cases of CAs and death (in perinatal period or later), the data from pathological examinations were used for diagnostic validity. Maximum age at diagnosis was as follows: for most cases, up to the end of the first week after delivery; for selected malformations (CHD, urogenital), up to the end of the first year of life; in some cases (multiple anomalies) a follow-up was performed.

Along with the physical examination, additional methods were used for identification of the genetic causes of CAs: family history and pedigree; laboratory genetic testing (conventional cytoge- 
netic analysis, biochemical and DNA analysis). In some cases (particularly those with multiple anomalies) dysmorphologic evaluation and search for syndromes, features and references was done by a clinical geneticist, using different sources: dysmorphology literature, "Smith's recognizable pattern of human malformation" [8], OMIM [7], London Dysmorphology Databases. Environmental causes were identified via interview (a careful history of pregnancy), questionnaire, clinical assessment and laboratory confirmation.

Data Analysis and Statistics. All analyses were based on the number of cases in the anomaly category of interest, not the number of anomalies. The study was approved by the Ethics Committee of the Medical University, Pleven, Buglaria. Informed consent was obtained from the parents in all cases of CAs.
The calculation of the total prevalence and live birth prevalence was conducted using the EUROCAT recommendations [6]. Confidence intervals (95\% CIs) were calculated for the total and live birth prevalence. The $\chi 2$ test for trends was used to compare differences in prevalence over time. A $p$ value of $<0.05$ was considered to be significant. Statistical analysis was performed using SPSS for Windows, v. 13.1.

\section{RESULTS}

During the study period (1988-2006), a total of 1,225 cases (1,115 live births, 72 stillbirths and 38 terminations of pregnancy) with CAs were ascertained. Table 1 presents the total number of CAs, the total, and live birth prevalence. The overall total prevalence of CAs was 25.72 (95\% CI 24.3 to 27.15)

Table 1. Total and live birth prevalence of congenital anomalies in the Pleven region, Bulgaria, 1988-2006

\begin{tabular}{|c|c|c|c|c|c|c|}
\hline Year & $\begin{array}{l}\text { Number of } \\
\text { CA Cases }\end{array}$ & $\begin{array}{l}\text { Number of } \\
\text { Births }^{b}\end{array}$ & $\begin{array}{c}\text { Prevalence per } 1,000 \\
\text { Births }^{\mathrm{b}}(95 \% \mathrm{CI})\end{array}$ & $\begin{array}{l}\text { CA Cases in } \\
\text { Live Births }\end{array}$ & $\begin{array}{l}\text { Number of } \\
\text { Live Births }\end{array}$ & $\begin{array}{c}\text { Live Birth Prevalence } \\
\text { per } 1,000(95 \% \text { CI })\end{array}$ \\
\hline 1988 & 64 & 3,604 & $17.76(13.45$ to 22.07$)$ & 59 & 3,586 & $16.45(12.29$ to 20.62$)$ \\
\hline 1989 & 75 & 3,453 & $21.72(16.86$ to 26.58$)$ & 64 & 3,422 & $18.70(14.16$ to 23.24$)$ \\
\hline 1990 & 64 & 3,421 & $18.71(14.17$ to 23.25$)$ & 61 & 3,409 & $17.89(13.44$ to 22.34$)$ \\
\hline 1991 & 74 & 3,130 & 23.64 (18.32 to 28.96$)$ & 68 & 3,112 & 21.85 (16.71 to 26.99$)$ \\
\hline 1992 & 80 & 2,905 & $27.54(21.59$ to 33.49$)$ & 75 & 2,875 & $26.09(20.26$ to 31.91$)$ \\
\hline 1993 & 83 & 2,670 & $31.09(24.50$ to 37.67$)$ & 80 & 2,652 & $30.16(23.66$ to 36.68$)$ \\
\hline 1994 & 69 & 2,627 & $26.26(20.15$ to 32.38$)$ & 64 & 2,607 & 24.54 (18.61 to 30.49$)$ \\
\hline 1995 & 57 & 2,373 & 24.01 (17.86 to 30.18$)$ & 53 & 2,354 & $22.51(16.52$ to 28.51$)$ \\
\hline 1996 & 60 & 2,370 & $25.32(18.99$ to 31.64$)$ & 56 & 2,351 & 23.82 (17.66 to 29.98$)$ \\
\hline 1997 & 47 & 2,002 & $23.48(16.84$ to 30.11$)$ & 39 & 1,983 & $19.67(13.56$ to 25.78$)$ \\
\hline 1998 & 60 & 2,099 & $28.58(21.46$ to 35.71$)$ & 55 & 2,083 & $26.40(19.52$ to 33.29$)$ \\
\hline 1999 & 66 & 2,318 & $28.47(21.70$ to 35.24$)$ & 61 & 2,297 & $26.56(19.98$ to 33.13$)$ \\
\hline 2000 & 48 & 2,229 & $21.53(15.51$ to 27.56$)$ & 47 & 2,209 & $21.28(15.26$ to 27.29$)$ \\
\hline 2001 & 83 & 2,072 & $40.06(31.61$ to 48.50$)$ & 70 & 2,047 & $34.20(26.32$ to 42.07$)$ \\
\hline 2002 & 64 & 1,940 & $33.00(25.04$ to 40.94$)$ & 58 & 1,914 & $30.30(22.62$ to 37.98$)$ \\
\hline 2003 & 57 & 1,930 & 29.53 (21.98 to 37.09$)$ & 51 & 1,919 & $26.58(19.38$ to 33.77$)$ \\
\hline 2004 & 49 & 2,124 & 23.07 (16.69 to 29.45$)$ & 47 & 2,111 & $22.26(15.97$ to 28.56$)$ \\
\hline 2005 & 59 & 2,110 & $27.96(20.93$ to 35.00$)$ & 49 & 2,083 & $23.52(17.02$ to 30.03$)$ \\
\hline 2006 & 66 & 2,245 & $29.40(22.41$ to 36.39$)$ & 58 & 2,215 & $26.18(19.53$ to 32.84$)$ \\
\hline Total & 1,225 & 47,622 & $25.72(24.3$ to 27.15$)$ & 1,115 & 47,229 & $23.61(22.24$ to 24.98$)$ \\
\hline
\end{tabular}

${ }^{a}$ Congenital anomalies occurring in live births, stillbirths (including fetal deaths at $\geq 20$ weeks of gestation) and terminated pregnancies.

${ }^{\mathrm{b}}$ Live births and stillbirths. 
per 1,000 births over the study period. There was a significant increase in total prevalence from 17.76 (95\% CI 13.45 to 22.07 ) per 1,000 births in 1988 to 29.40 (95\% CI 22.41 to 36.39$)$ in 2006 ( $\chi 2=5.03$; $p=0.025)$. There were 47,229 live births and 1,115 live births with CAs, giving an overall live birth prevalence of 23.61 (95\% CI 22.24 to 24.98) per 1,000 live births. There was a significant increase in live birth prevalence from 16.45 (95\% CI 12.29 to 20.62) per 1,000 live births in 1988 to $26.18(95 \%$ CI 19.53 to 32.84$)$ in 2006 ( $\chi 2=4.27 ; p=0.039$ ).

Table 2 summarizes the main types of CA; number, proportion ( $\%$ of all cases registered) and prevalence (per 1,000 registered births). Higher rates were notified for CHD (4.3 per 1,000), all nervous system CAs $(3.3$ per 1,000$)$, limb defects $(2.5$ per 1,000$)$. Neural tube defects showed a total prevalence of 2.0 per 1,000 per registered births, and about $20 \%$ of all cases of this defect resulted in termination of preg- nancy. Most of the CHD cases (80\%) were ascertained in the nenonatal period of live born babies or in stillbirths (based on active screening). About 20\% of the cases were diagnosed in the post neonatal period up to the end of the first year of life of the babies (some cases were identified via case records from the Department of Pediatrics, University Hospital, Pleven, Bulgaria).

The total prevalence of most CAs remained stable over the study period. However, there was a trend towards a significant increase in the total prevalence of specific anomalies: digestive system anomalies $\left(\chi^{2}=4.48 ; p=0.034\right)$, tumors (mostly teratomas) $\left(\chi^{2}=4.98 ; p=0.026\right)$, musculoskeletal and connective tissue anomalies (mainly gastroschisis) $\left(\chi^{2}=5.52 ; p=0.019\right)$, non syndromal dysmorphologic conditions $(\chi 2=6.77 ; p=0.009)$.

Table 3 summarizes the main causes of registered CAs, number of cases, proportion $(\%$ of all

Table 2.The main types of congenital anomaly in all registered births (1988-2006), number, proportion (\% of all cases) and prevalence (per 1,000 births)

\begin{tabular}{|c|c|c|c|}
\hline Congenital Anomaly & $\begin{array}{l}\text { Number } \\
\text { of Cases }\end{array}$ & $\begin{array}{c}\text { Proportion } \\
\text { (\%) }\end{array}$ & $\begin{array}{l}\text { Total Prevalence } \\
\text { per } 1,000 \text { Births }\end{array}$ \\
\hline $\begin{array}{l}\text { Isolated congenital anomalies }^{\mathbf{a}} \\
\text { Neural tube defects } \\
\text { Other CAs of nervous system } \\
\text { Eye } \\
\text { Ear } \\
\text { Congenital heart disease } \\
\text { Respiratory system } \\
\text { Cleft palate and cleft lip } \\
\text { Digestive system } \\
\text { External genital system } \\
\text { Internal urogenital system } \\
\text { Limb } \\
\text { Musculoskeletal and connective tissue } \\
\text { Skin } \\
\text { Endocrine glands } \\
\text { Tumors } \\
\text { Subtotal }\end{array}$ & $\begin{array}{c}96 \\
62 \\
3 \\
9 \\
204 \\
4 \\
51 \\
66 \\
65 \\
22 \\
121 \\
62 \\
54 \\
3 \\
10 \\
\mathbf{8 3 2}\end{array}$ & $\begin{array}{c}7.8 \\
5.1 \\
0.2 \\
0.7 \\
16.7 \\
0.3 \\
4.2 \\
5.4 \\
5.3 \\
1.8 \\
9.9 \\
5.1 \\
4.4 \\
0.2 \\
0.8 \\
\mathbf{6 8 . 0}\end{array}$ & $\begin{array}{c}2.02 \\
1.30 \\
0.06 \\
0.19 \\
4.29 \\
0.08 \\
1.07 \\
1.39 \\
1.37 \\
0.46 \\
2.54 \\
1.30 \\
1.13 \\
0.06 \\
0.21 \\
\mathbf{1 7 . 4 7}\end{array}$ \\
\hline $\begin{array}{l}\text { Multiple congenital anomalies } \\
\text { Chromosomal abnormalities } \\
\text { Single gene and sporadic malformation syndromes } \\
\text { Non syndromal conditions } \\
\text { Environmental abnormalities } \\
\text { Multiple anomalies of unknown etiology } \\
\text { Subtotal }\end{array}$ & $\begin{array}{c}100 \\
109 \\
40 \\
34 \\
110 \\
393\end{array}$ & $\begin{array}{c}8.2 \\
8.9 \\
3.3 \\
2.8 \\
9.0 \\
\mathbf{3 2 . 0}\end{array}$ & $\begin{array}{l}2.10 \\
2.29 \\
0.84 \\
0.71 \\
2.31 \\
\mathbf{8 . 2 5}\end{array}$ \\
\hline Total & 1,225 & 100.0 & 25.72 \\
\hline
\end{tabular}

a The classification of isolated CA is according to EUROCAT.

${ }^{b}$ The classification of multiple CA is personal. 
Table 3. Causes of congenital anomalies: number of case, proportion ( $\%$ of all causes) and prevalence (per 1,000 registered births)

\begin{tabular}{|l|c|c|c|}
\hline \multicolumn{1}{|c|}{ Cause } & $\begin{array}{c}\text { Number } \\
\text { of Cases }\end{array}$ & $\begin{array}{c}\text { Proportion } \\
\text { (\%) }\end{array}$ & $\begin{array}{c}\text { Total Prevalence } \\
\text { per 1,000 Births }\end{array}$ \\
\hline Genetic & & & 2.10 \\
Chromosomal & 100 & 8.2 & 3.53 \\
Single gene & $168^{\mathrm{a}}$ & 13.7 & 10.20 \\
Multifactorial & 486 & 39.7 & $\mathbf{1 5 . 8 3}$ \\
Subtotal & $\mathbf{7 5 4}$ & $\mathbf{6 1 . 5}$ & 0.12 \\
\hline Environmental & & & 0.44 \\
Drugs and chemicals & 6 & 0.5 & 0.19 \\
Infections & 21 & 1.7 & 0.96 \\
Maternal illness & 9 & 0.7 & $\mathbf{1 . 7 2}$ \\
Mechanical uterine factors & 46 & 3.8 & $\mathbf{8 . 1 7}$ \\
Subtotal & $\mathbf{8 2}$ & $\mathbf{6 . 7}$ & $\mathbf{2 5 . 7 2}$ \\
\hline Unknown & $\mathbf{3 8 9}$ & $\mathbf{3 1 . 8}$ & $\mathbf{1 0 0 . 0}$ \\
\hline Total & $\mathbf{1 2 2 5}$ & & \\
\hline
\end{tabular}

a The number of single gene disorders included single gene malformation syndromes plus isolated anomalies due to single gene defects.

cases registered) and prevalence (per 1,000 registered births). The most common CAs were those due to genetic causes (chromosomal, single gene, multifactorial), with a total prevalence of 15.8 per 1,000 registered births over the study period.

\section{DISCUSSION}

The congenital anomalies registered in this study comprise mostly major CAs and do not include some minor anomalies. It is therefore difficult to compare the determined total prevalence in our study with the data from other studies with a specific anomalies inclusion and exclusion list, as well as with a different way of calculation of the prevalence $[6,9,10]$.

The overall total prevalence of CAs in this study was 25.72 per 1,000 births, which is similar to the total prevalence in other studies[11-14], and to the average rate for all full members' registries of EUROCAT (22.11 per 1000 births over time (19802005) [1]. The reported trend in prevalence of CAs is different for the registries. The registries in France, Belgium, Malta, Switzerland, Spain, Croatia and Italy reported increasing rates over time (1980-2005), while others like the British, Irish, Dutch and Danish registries, reported a declining trend.

The present study demonstrated an overall significant upward trend in the prevalence of CAs as a whole (total and live birth prevalence) from 1988 to 2006 in the Pleven region. However, there was a significant increase in the total prevalence only of specific anomalies: digestive system, tumors, gastroschisis and non syndromal dysmorphologic conditions. The potential underlying contributing factors that should be considered for explanation of regional and secular trends are: case ascertainment methods; improving antenatal screening; some demographic and environmental factors $[9,15,16]$.

In this study, due to the relatively consistent methodology used in the registration of CA cases, we think that the case ascertainment and diagnostic methods play a minor role in data collection over time. In our study, the types of CA that have recently demonstrated an upward trend in prevalence have unclear genetics or a minor genetic impact and an important role of environmental factors in their etiology. That is why more attention should be paid to these factors in the future and further epidemiological studies are needed. For example, concerning gastroschisis there is a significant difference in the reported prevalence between EUROCAT registries, suggesting a geographical gradient in the prevalence of this defect [1,9]. The phenomenon of increasing gastroschisis prevalence in Europe (1980-2002), according to some authors [17], is not restricted to younger mothers only. In the present study, the upward trend in gastroschisis prevalence is without a 
rise in the proportion of teenage mothers. There is evidence that maternal exposure to vasoconstrictive drugs and cigarette smoking may increase the risk of gastroschisis and small intestinal atresia [18]. This hypothesis is suitable to be tested in a future study, in relation to the changes in socioeconomic status of the Bulgarian population over the study period and expansion of some habits such as cigarette smoking.

The most common type of CAs we found were cardiac defects (16.7\% of all anomalies), with a total prevalence rate of 4.3 per 1,000 births. The overall prevalence rate of CHD reported by EUROCAT over the period (1990-2005) was 6.77 per 1,000 births, with a variation of the rate seen across the different registries (from 4.49 per 1,000 for Zagreb, Croatia to 8.71 per 1,000 for Odense, Island of Fyn, Denmark) [1]. This variation reflects the difference of the availability and accuracy of antenatal diagnosis, the ascertainment of late post neonatally diagnosed cardiac defects, the possibility for close relation with a pediatric cardiologist and the expertise to accurately diagnose [9].

Neural tube defects are among the most common CAs that cause fetal and neonatal death around the world $[5,19]$. EUROCAT reported the overall prevalence rate of NTD at 1.05 per 1,000 births over the period 1990-2005 (Zagreb, Croatia 0.5 per 1,000 births, Glasgow, Scotland, UK 1.7 per 1,000 , Paris, France 1.3 per 1,000) [1]. There is a variation $(0 \%$ for Malta and Ireland, $22.0 \%$ for the Netherlands, $92.0 \%$ for France) in the proportion of NTD cases resulting in pregnancy termination, seen across the different registries and countries in Europe, influenced by the differences in screening policies, culture and legislation. The countries that did not have a policy for offering routine scans had a significantly lower prenatal detection rate of NTD [20].

The present study showed a relatively high prevalence rate of NTD in the Pleven region (2.0 per 1,000 births) compared to other registers and parts of Europe [1] and about $20.0 \%$ of all registered cases of NTD were detected in terminated pregnancies after prenatal diagnosis. Since in all the cases of prenatal diagnosis of NTD there was termination of the pregnancy, the data demonstrate inadequate prenatal screening for these defects in the Pleven region. Although in recent years the national policy recommended periconceptional folic acid supplementation, the prevalence rate of NTD in the Pleven region remained stable over the study period. These factors raise the issue of introducing an official countrywide policy for routine ultrasound anomaly scanning as an element of prevention approaches.

Our study revealed three important findings: 1) genetic components were identified in approximately $62.0 \%$ of all CA cases; $22.0 \%$ of all cases had a clear genetic cause (chromosomal $8.0 \%$ or single gene defects $14.0 \%$ ) and $40.0 \%$ multifactorial etiology. The data demonstrate a high proportion of affected families with a high recurrence risk, and emphasize the importance of offering genetic counseling and prenatal diagnosis to mothers who have previously had an abnormal baby/pregnancy. 2) The etiology of one-third of the CAs was unknown or unclear. 3) Environmental causes were infrequent (approximately $7.0 \%$ of all CA cases).

In other studies [21-23], the reported genetic contribution of CAs is similar: chromosomal abnormalities $6.0-10.0 \%$, single gene defects $7.0-17.0 \%$, multifactorial etiology 20.0-30.0\%. Environmental causes have been identified in $5.0-10.0 \%$ of birth defects and unknown causes in $40.0-50.0 \%$ of all cases. The lower proportion of CAs with unknown etiology established in our study may be due to the lower number of births (from 2,000 to 3,000 annually), which allows an accuracy of diagnosis and reflects the interest to identify a specific etiology.

In conclusion, the epidemiological data of this study suggest that $2.0-3.0 \%$ of all births (approximately 1 in 40 births every year) are associated with CAs. The particular pattern of CAs in the Pleven region and the increasing trend in prevalence of specific anomalies, draw attention to the role of specific environmental or may be local risk factors for those anomalies, and require further regional epidemiological studies. The high proportion of genetic factors in the causes of CA emphasize the importance of genetic counseling services as an integral part of preventive medical care.

\section{ACKNOWLEDGMENTS}

We wish to acknowledge colleagues at the Department of Obstetrics and Gynaecology, Clinic of Neonatology and all participants in the regional registry of congenital anomalies at the University 
Hospital City of Pleven, for their assistance with data collection. We thank Professor Emil Simeonov (Department of Paediatrics, Medical Faculty, Sofia, Bulgaria) for his expert help in the analyses of the genetic causes.

\section{REFERENCES}

1. EUROCAT. Publications and data 1980-2005: Prevalence data tables (http://www.eurocat.ulster.ac.uk/ pubdata/tables.html).

2. Kalter H. Five-decade international trends in the relation of perinatal mortality and congenital malformations: stillbirth and neonatal death compared. Int J Epidemiol 1991; 20(1): 173-179.

3. Rosano A, Botto LD, Botting B, Mastroiacovo P. Infant mortality and congenital anomalies from 1950 to 1994: an international perspective. J Epidemiol Community Health 2000; 54(9): 660-666.

4. Wen SW, Liu S, Joseph KS, Trouton K, Allen A. Regional patterns of infant mortality caused by lethal congenital anomalies. Can J Public Health 1999; 90(5): 316-319.

5. Wen SW, Liu S, Joseph KS, Rouleau J, Allen A. Patterns of infant mortality caused by major congenital anomalies. Teratology 2000; 61(5): 342-346.

6. EUROCAT. Guide 1.3 Instructions for the registration and surveillance of congenital anomalies. (http://www. eurocat.ulster.ac.uk/surveillance/prevalencerates.html).

7. McKusick V. Online Mendelian Inheritance in Man. Online website: http://www.ncbi.nlm.nih.gov/ omim.

8. Jones KL. Smith's Recognizable Patterns of Human Malformations, 5th ed. Philadelphia: WB Saunders Company, 1997.

9. Rankin J, Pattenden S, Abramsky L, Boyd P, Jordan H, Stone D, Vrijheid D, Wellesly D, Dolk H. Prevalence of congenital anomalies in five British regions, 1991-99. Arch Dis Child Fetal Neonatal Ed 2005; 90(5): F374-379.

10. International Clearinghouse for Birth Defects Surveillance and Research. ICBDSR Annual Report 2006. Introduction. Calculation of rate (http://www. icbdsr.org/ filebank/documents/Report2006.pdf).

11. EUROCAT. EUROCAT Annual Report to WHO 2005 (http://www.eurocat.ulster.ac.uk/pdf/EUROCAT-Annual-Report-2005-for-WHO.pdf).

12. Richards ID, Bentley HB, Glenny AM. A local congenital anomalies register: monitoring preventive interventions. J Public Health Med 1999; 21(1): 37-40.

13. Seto T, Nakagawa H, Morikawa Y, Nishijo M, Miura K, Kadoshima Y. Trend of congenital anomalies over 20 years ascertained by population-based monitoring in Ishikawa Prefecture, Japan. Congenit Anom (Kyoto) 2003; 43(4): 286-293.

14. Sipek A, Gregor V, Horacek J, Masatova D. Analysis of congenital defects contributing to perinatal mortality in Czech Republic. Ceska Gynekol 2003; 68(6): 389-394.

15. Dastgiri S, Stone DH, Le-Ha C, Gilmour WH. Prevalence and secular trend of congenital anomalies in Glasgow, UK. Arch Dis Child 2002; 86(4): 257-263.

16. Hobbs CA, Hopkins SE, Simmons CJ. Sources of variability in birth defects prevalence rates [abstract]. Teratology 2001; 64(suppl 1): S8-S13.

17. Loane M, Dolk H, Bradbury and a EUROCAT Working Group. Increasing prevalence of gastroschisis in Europe 1980-2002: a phenomenon restricted to younger mothers? Paediatr Perinat Epidemiol 2007; 21(4): 363-369.

18. Werler MM, Sheehan JE, Mitchell AA. Association of vasoconstrictive exposure with risks of gastroschisis and small intestinal atresia. Epidemiology 2003; 14(3): 349-354.

19. Dastgiri S, Gilmour WH, Stone DH. Survival of children born with congenital anomalies. Arch Dis Child 2003; 88(5): 391-394.

20. Boyd PA, de Vigan C, Khsohnood B, Loane M, Garne E, Dolk H, EUROCAT Working Group. Survey of prenatal screening policies in Europe for structure malformations and chromosome anomalies, and their impact on detection and termination rates for neural tube defects and Down's syndrome. BJOG 2008; 115(6): 689-696.

21. Jorde LB, Carey JC, Bamshad MJ, White RL. Clinical genetics and genetic counseling. In: Jorde LB, Carey JC, Bamshad MJ, White RL, Eds. Medical Genetics, 3rd ed. Missouri: Mosby, an affiliate of Elsevier 2003; 305-325.

22. Kalter H, Warkany J. Congenital malformation: etiological factors and their role in prevention. $\mathrm{N}$ Engl $\mathrm{J}$ Med 1983; 308(8): 424-431.

23. Turnpenny PD, Ellard S. Congenital abnormalities and dysmorphic syndromes. In: Turnpenny PD, Ellard S, Eds. Emery's Elements of Medical Genetics, 12th ed. London: Churchill Livingstone 2005; 247-262. 